УДК 630*161(470.44/.47)

ГЕНЕРАТИВНЫЕ ОСОБЕННОСТИ И РОСТ СОСНЫ ОБЫКНОВЕННОЙ

НА ПЛАНТАЦИЯХ ВЕГЕТАТИВНОГО И СЕМЕННОГО ПРОИСХОЖДЕНИЯ В СУХОЙ СТЕПИ НИЖНЕГО ПОВОЛЖЬЯ

\author{
Иозус А.П., Завьялов А.А., Бойко С.Ю.
}

Камынинский технологический институт (филиал) ФГБОУ ВО «Волгоградский государственный технический университет», Камышин, е-mail: ttp@kti.ru

В настоящее время перед отечественными лесоводами стоит задача полностью перевести семеноводство сосны в стране на селекционно-генетическую основу, для чего площадь селекционно-семенных плантаций должна быть значительно увеличена, так как семена с лесосеменных плантаций в России обеспечивают всего 15-20\% от их общей потребности, тогда как в Швеции и Финляндии до $100 \%$. При создании семенных плантаций прививка не гарантирует высокую активность репродуктивных процессов. Не имеет решающего значения и использование черенков с физиологически зрелых маточных деревьев. Под влиянием подвоя происходит определенное физиологическое омоложение привоя, вследствие чего возрастная динамика репродуктивного развития привитого растения несколько отличается от развития, выращенного из семян. Обилие женского и мужского цветения, урожай шишек, выход и полнозернистость семян, их масса и посевные качества определяются главным образом наследственно обусловленными репродуктивными свойствами представленных на плантациях клонов. В результате отдельные клоновые плантации не только не превосходят по семенной продуктивности плантации семенного происхождения, но и уступают им. При этом плантации семенного происхождения дешевле, устойчивее и долговечнее, обеспечивают большее генотипическое разнообразие семян. Установлено, что довольно тесной связью характеризуются клоны первого и второго поколений по обилию урожая, выходу и полнозернистости семян. Показатели генеративного развития полусибсовых семей не коррелируют, за небольшим исключением, с аналогичными показателями материнских клонов и одноименных клоновых потомств второго поколения. В сухой степи Нижнего Поволжья наибольший экономический эффект достигается при селекционном отборе на семенных плантациях по комплексу признаков, в этом случае его эффективность ощутимо увеличивается при возрастании его интенсивности с 20 до $40 \%$.

Ключевые слова: семенные плантации, вегетативное размножение, семенное размножение, генеративные показатели, эффективность селекционного отбора, клоновое потомство, полусибсовое потомство

\title{
GENERATIVE FEATURES AND GROWTH OF SCOTS PINE ON PLANTATIONS OF VEGETATIVE AND SEED ORIGIN IN THE DRY STEPPE OF THE LOWER VOLGA REGION
}

\author{
Iozus A.P., Zavyalov A.A., Boiko S.Yu. \\ Kamyshin Technological Institute (branch) of Volgograd State Technical University, \\ Kamyshin,e-mail: ttp@kti.ru
}

\begin{abstract}
Currently, domestic foresters are faced with the task of completely transferring pine seed production in the country to a selection and genetic basis, for which the area of selection and seed plantations should be significantly increased, since seeds from forest seed plantations in Russia provide only $15-20 \%$ of their total needs, while in Sweden and Finland up to $100 \%$. When creating seed plantations, grafting does not guarantee a high activity of reproductive processes. The use of cuttings from physiologically mature mother trees is also of no decisive importance. Under the influence of the rootstock, a certain physiological rejuvenation of the graft occurs, as a result of which the age dynamics of the reproductive development of the grafted plant is somewhat different from the development grown from seeds. The abundance of female and male flowering, the yield of cones, the yield and full grain of seeds, their mass and sowing qualities are mainly determined by the hereditary reproductive properties of the clones represented on the plantations. As a result, individual clone plantations are not only not superior to seed plantations of seed origin in terms of seed productivity, but also inferior to them. At the same time, seed plantations are cheaper, more stable and more durable, and provide a greater genotypic diversity of seeds. It is established that the clones of the first and second generations are characterized by a rather close relationship in terms of crop abundance, yield and full grain of seeds. Indicators of generative development of semi-sib families do not correlate, with a few exceptions, with similar indicators of maternal clones and second-generation clone progeny of the same name. In the dry steppe of the Lower Volga region, the greatest economic effect is achieved by selective selection on seed plantations according to a set of characteristics, in this case, its effectiveness significantly increases with an increase in its intensity from 20 to $40 \%$.
\end{abstract}

Keywords: seed plantations, vegetative reproduction, seed reproduction, generative indicators, efficiency of selection selection, clone offspring, semi-sib offspring

Семенные плантации сосны обыкновенной (Pinus sylvestris L.) создаются в нашей стране уже более пятидесяти лет. За этот период в постоянную лесосемен- ную базу зачислено свыше 10 тыс. га плантаций разного генетического уровня $[1 ; 2]$. В настоящее время перед отечественными лесоводами стоит задача полностью пере- 
вести семеноводство сосны в стране на селекционно-генетическую основу, для чего площадь селекционно-семенных плантаций должна быть значительно увеличена, так как, к сожалению, семена с лесосеменных плантаций в России обеспечивают всего 15-20\% от их общей потребности, тогда как в Швеции и Финляндии до $100 \%$ [1; 2]. Накопленный при эксплуатации плантаций сорокалетний опыт позволяет выделить наиболее перспективные направления дальнейшей работы по ведению плантационного семеноводства. При создании плантаций в основном используют вегетативный и семенной методы размножения плюсовых деревьев [1-3]. В последнее время определенное развитие получили технологии in vitro, но они требуют серьезных материальных вложений и пока не получили широкого распространения в практике лесного хозяйства. На основе опыта необходимо выделить основные направления создания селекционных семенных плантаций: клоновые, семейственные, популяционные, гибридные. Далее будет дана оценка особенностям роста и плодоношения клоновых, семейственных и популяционных плантаций в сухой степи Нижнего Поволжья, обоснована экономическая эффективность каждого из этих методов. Преимущества и недостатки вегетативного и семенного методов в общем хорошо известны [2-4]. Вместе с тем мало сравнительных экспериментальных данных о репродуктивном развитии одновозрастных привитых и непривитых деревьев, практически отсутствуют сведения о селекционном и экономическом эффектах, получаемых при использовании семян с клоновых и семейственных плантаций.

Цель исследования провести комплексную селекционно-экономическую оценку эксплуатации семенных плантаций сосны в сухой степи Нижнего Поволжья. На основе анализа сравнить эффективность разных способов отбора сосны по росту, состоянию, урожайности клонов и семей на семенных плантациях.

\section{Материалы и методы исследования}

Объектами исследования являлись комплекс лесосеменных плантаций, заложенных в Новоаннинском лесхозе в 19831988 годах на площади 160 га. Селекционно-семеноводческий комплекс включал в себя клоновые, семейственные и популяционные плантации. С момента создания и по настоящее время на объекте проводи- лись наблюдения за ростом, состоянием, урожайностью селекционного материала.

\section{Результаты исследования и их обсуждение}

На протяжении 35 лет в Волгоградской области (Новоаннинский селекционно-семеноводческий комплекс) изучали семеноношение и рост сосны на плантациях вегетативного и семенного происхождения второго поколения, которые были заложены в 1983-1988 гг. путем размножения селекционного материала, прошедшего первичную селекционную оценку в вегетационных опытах на засухо-, соле- и морозоустойчивость потомства, а также на клоновых плантациях первого поколения, заложенных в 1972-1974 гг. в Волгоградском лесхозе на площади 2 га, с использованием 35 клонов с отобранных лучших по фенотипу деревьев в насаждениях области [3; 4].

Выявлено, что клоновые плантации сосны в условиях сухой степи характеризуются ранним женским цветением. Единичные макростробилы появляются на второй-третий год после прививки (возраст подвоев 3-5 лет), а к 5-6 годам цветет уже 70-90\% растений, и среднее число стробилов на них 7-15; к концу первого десятилетия они образуются практически на всех привоях - по 200-400 шт. Семенные потомства вступают в репродуктивную фазу несколько позднее. На шестой год после посадки 2-летних сеянцев единичное женское цветение отмечено у $50 \%$ растений, через 3-5 лет - у 70-80\% (по 40-60 шт.). Преимущество клоновых плантаций по урожаю шишек сохраняется примерно до 15-летнего возраста, затем различия постепенно исчезают, что отмечалось и в других 3онах [3-5]. В целом за 25 лет суммарный урожай семян с 1 га изучаемой клоновой плантации был лишь на $5 \%$ выше, чем на расположенной в аналогичных условиях одновозрастной плантации семенного происхождения. Разницы в плодоношении популяционных и семейственных плантаций не отмечено.

В данной зоне средний ежегодный урожай семян на 15-25-летних плантациях независимо от метода их закладки составляет 3-3,5, в урожайные годы - до 7,5 кг/га.

Возрастная динамика мужского цветения привитых и непривитых сосен существенно не различается. Единичные микростробилы появляются на четвертый-пятый год после прививки черенков или посадки сеянцев. В 6 лет они формируются у 21- 
$84 \%$ растений (в среднем - соответственно от 8 до 150 мужских побегов на дереве), на 1 га пыльцы продуцируется от нескольких граммов до 0,3-0,5 кг, в 8-12 лет - 1,510, в 15-20 лет продуцируют уже 20-30 кг и более. Удовлетворительной обеспеченность плантаций собственной пыльцой можно считать с 10-12 лет [3; 4; 6].

Анализ полученных данных показывает, что прививка как технологический прием сама по себе не гарантирует высокую активность репродуктивных процессов. Не имеет решающего значения и использование черенков с физиологически зрелых маточных деревьев. Под влиянием подвоя происходит определенное физиологическое омоложение привоя, вследствие чего возрастная динамика репродуктивного развития привитого растения не столь резко, как этого можно было ожидать, отличается от развития выращенного из семени. Обилие женского и мужского цветения, урожай шишек, выход и полнозернистость семян, их масса и посевные качества определяются главным образом наследственно обусловленными репродуктивными свойствами представленных на плантациях клонов. В результате отдельные клоновые плантации не только не превосходят по семенной продуктивности плантации семенного происхождения, но и уступают им. Установлено, что плантации семенного происхождения дешевле, устойчивее и долговечнее, обеспечивают большее генотипическое разнообразие семян.

В конце первого после закладки десятилетия на клоновых плантациях деревья на 20\% ниже непривитых. Относительная быстрота роста клоновых и семенных потомств одних и тех же плюсовых деревьев различается весьма существенно (коэффициент линейной корреляции равен -0,4). Слабо коррелирует высота клоновых потомств и с размерами плюсовых деревьев $(0,34)$. По-видимому, это обусловлено влиянием подвоев, характером срастания и иными факторами, определяющими рост привитых сосен. Следовательно, по значениям данного показателя нельзя судить о генетической ценности плюсовых деревьев.

Полученные данные позволяют сделать вывод, что при закладке плантаций сосны первого поколения вегетативный метод размножения лучших фенотипов, не проверенных по потомству, не имеет заметных преимуществ перед семенным как по урожайности, так и по селекционной ценности семян. Достоинства вегетатив- ного метода заключаются в следующем: он дает возможность оценивать клоновое потомство по устойчивости и репродуктивным особенностям, получать в необходимых количествах семена для закладки испытательных культур; кроме того, создание клоновых плантаций - одно из направлений сохранения ценного генетического фонда сосны. Плантации семенного происхождения дешевле, устойчивее и долговечнее, обеспечивают большее генотипическое разнообразие семян; при выращивании потомства плюсовых деревьев раздельно по фиксированным схемам они могут одновременно успешно выполнять роль испытательных культур. Создание плантаций первого поколения - первый этап перевода лесного семеноводства на селекционно-генетическую основу и преследует цели: отбор и сохранение выдающихся по фенотипу деревьев; генетическое улучшение семян; организацию генетической проверки плюсовых деревьев. Осуществление этих целей создает предпосылки для перехода ко второму этапу - закладке плантаций второго поколения с использованием элитных деревьев, генетическая ценность которых выявляется по результатам испытания клонового и семенного потомств.

В конце второго десятилетия существенных различий по росту в высоту и диаметру между клоновыми, семейственными и популяционными плантациями не отмечается, что сохраняется и настоящее время в возрасте 35 лет.

Многолетними наблюдениями установлено, что присущие клонам сосны репродуктивные особенности, такие как сроки весеннего развития мужских и женских генеративных органов, обилие цветения, тип сексуализации, величина и повторяемость урожаев, выход и полнозернистость семян, в основном сохраняются при повторном вегетативном размножении [3; 4; 7]. Особо надо отметить, что характер репродуктивного развития привоев не зависит от того, в какой части кроны маточного дерева заготовлен черенок для прививки и какой у побега половой тип (мужской или женский) либо ростовой. Что же касается семенных потомств, то для них характерна значительная изменчивость по генеративным особенностям. Причем средние для той или иной семьи показатели репродуктивной деятельности, как правило, не совпадают с таковыми у материнского дерева.

Поскольку изменчивость генеративных признаков не соответствует закону нор- 
мального распределения, для анализа связи между показателями родительских деревьев и их вегетативных и семенных потомств нами использован непараметрический критерий сравнения, в частности коэффициент ранговой корреляции Спирмена (табл. 1).

Таблица 1

Изменчивость генеративных показателей родительских деревьев и их вегетативных и семенных потомств

\begin{tabular}{|l|c|c|}
\hline \multicolumn{1}{|c|}{$\begin{array}{c}\text { Генеративные } \\
\text { показатели }\end{array}$} & $\begin{array}{c}\text { Сравниваемые } \\
\text { пары }\end{array}$ & $\begin{array}{c}\text { Коэффициент } \\
\text { корреляции }\end{array}$ \\
\hline Урожай шишек & $\begin{array}{c}\text { Кл. 1 - кл. 2 } \\
\text { Кл. 1 - семьи }\end{array}$ & $\begin{array}{c}0,58 \\
-0.16\end{array}$ \\
\hline $\begin{array}{l}\text { Шишки: } \\
\text { длина }\end{array}$ & Кл. 1 - кл. 2 & 0,52 \\
& Кл. 1 - семьи & $-0,38$ \\
\hline масса шишки & Кл. 1 - кл. 2 & 0,33 \\
& Кл. 1 - семьи & 0,31 \\
\hline число семян & Кл. 1 - кл. 2 & 0,59 \\
в шишке & Кл. 1 - семьи & 0,65 \\
\hline Семена: & Кл. 1 - кл. 2 & 0,86 \\
полнозернистость & Кл. 1 - семьи & $-0,02$ \\
\hline масса 1000 штук & Кл. 1 - кл. 2 & 0,25 \\
& Кл. 1 - семьи & 0,03 \\
\hline
\end{tabular}

Установлено, что довольно тесной связью характеризуются клоны первого и второго поколений по обилию урожая, выходу и полнозернистости семян; в меньшей степени сохраняется при вегетативном размножении ранговое положение их по массе шишек и семян, размерам первых. Показатели генеративного развития полусибсовых семей не коррелируют, за небольшим исключением, с аналогичными показателями материнских клонов и одноименных клоновых потомств второго поколения.
Таким образом, путем отбора и вегетативного размножения плюсовых (элитных) деревьев, характер генеративной деятельности которых изучен в клоновом потомстве (в клоновых архивах, на плантациях первого поколения), на клоновых плантациях второго поколения можно регулировать синхронность цветения, сбалансированное соотношение мужских и женских генеративных органов (что необходимо для обеспечения перекрестного опыления), урожай и качество семян. При семенном размножении из-за слабого наследования в потомстве репродуктивных особенностей материнских деревьев осуществлять это селекционными методами практически нельзя, что ограничивает их применение.

Вегетативный метод создания плантаций второго поколения позволяет улучшить генетические свойства семян за счет использования клонов с высокой комбинационной способностью. По нашим данным, в 12-летнем возрасте примерно $40 \%$ полусибсовых потомств сосны имеют достоверное (11-25\%) преобладание по средней высоте над контролем (культуры из семян популяционного сбора). По результатам корреляционного анализа, стабилизация рангового положения семей в испытуемой совокупности наступает в 6-7 лет, возраст этот следует считать минимально допустимым для оценки комбинационной способности плюсовых деревьев.

С целью изучения эффективности отбора с использованием метода дисперсионного анализа проранжировали данные по росту и урожайности клонов и полусибсов на плантации Новоаннинского лесного семеноводческого центра. Оценили эффективность отбора $20 \%$ и $40 \%$ интенсивности (табл. 2).

Таблица 2

Сравнение разных способов селекционного отбора сосны обыкновенной в сухой степи Нижнего Поволжья

\begin{tabular}{|c|c|c|c|c|c|}
\hline \multirow[t]{2}{*}{ Показатели отбора } & \multirow[t]{2}{*}{$\begin{array}{l}\text { Интенсивность } \\
\text { отбора, \% }\end{array}$} & \multicolumn{4}{|c|}{$\begin{array}{c}\text { Относительная эффективность отбора } \\
\text { к среднему рангу по варианту, \% }\end{array}$} \\
\hline & & $\begin{array}{l}\text { Отбор по росту } \\
\text { полусибсов }\end{array}$ & \begin{tabular}{|l} 
Отбор по уро- \\
жайности \\
\end{tabular} & $\begin{array}{l}\text { Отбор по ро- } \\
\text { сту клонов }\end{array}$ & $\begin{array}{c}\text { Отбор } \\
\text { по комплексу }\end{array}$ \\
\hline \multirow{2}{*}{$\begin{array}{l}\text { По средней урожай- } \\
\text { ности }\end{array}$} & 20 & 115 & 130 & 102 & 122 \\
\hline & 40 & 120 & 160 & 91 & 130 \\
\hline \multirow{2}{*}{ По росту полусибсов } & 20 & 131 & 114 & 111 & 130 \\
\hline & 40 & 165 & 122 & 105 & 146 \\
\hline \multirow{2}{*}{$\begin{array}{l}\text { По росту клонового } \\
\text { потомства }\end{array}$} & 20 & 106 & 103 & 131 & 110 \\
\hline & 40 & 107 & 93 & 165 & 130 \\
\hline
\end{tabular}


Как видно из результатов отбора, в сухой степи Нижнего Поволжья наибольший экономический эффект достигается по комплексу признаков, в этом случае эффективность отбора ощутимо увеличивается при возрастании его интенсивности с 20 до $40 \%$.

Поэтому наиболее целесообразным является вариант отбора клонов по урожайности и росту семенного и вегетативного потомства. При ранжировании показателей клонов отбирать надо те, что набрали наименьшую сумму рангов по комбинационной способности и семенной продуктивности. Их широкая репродукция на плантациях следующего уровня обеспечит повышение урожайности на 30-50\%, при этом продуктивность насаждений может возрасти на 10-12\%. Отбор по комплексу признаков, по сравнению с отбором по одному из показателей, позволит одновременно улучшить генетические свойства семян и повысить урожайность.

Кроме использования на плантации потомства высокоурожайных клонов, можно применять и агротехнические приемы стимулирования урожайности, и обязательны эффективные меры борьбы с вредителями и болезнями. Однако, по нашим данным [3; 4], определяющее значение для плодоношения и семенных плантаций и сосновых насаждений в целом имеют погодные условия года, предшествующего закладке генеративных органов. Именно они определяют периодичность плодоношения сосны. Много также зависит от энтомовредителей и болезней, из-за которых можно потерять до $80 \%$ урожайности.

\section{Выводы}

1. При закладке плантаций сосны первого и второго поколения вегетативный метод размножения лучших фенотипов, не проверенных по потомству, не имеет заметных преимуществ перед семенным как по урожайности, так и по селекционной ценности семян.

2. Установлено, что довольно тесной связью характеризуются клоны первого и второго поколений по обилию урожая, выходу и полнозернистости семян. Показатели генеративного развития полусибсовых семей не коррелируют, за небольшим исключением, с аналогичными показателями материнских клонов и одноименных клоновых потомств второго поколения.

3. В сухой степи Нижнего Поволжья наибольший экономический эффект дости- гается при отборе по комплексу признаков, в этом случае его эффективность ощутимо увеличивается при возрастании интенсивности с 20 до $40 \%$.

\section{Список литературы / References}

1. Царев А.П. Программы лесной селекции в России и за рубежом: монография. М.: Изд-во Московского государственного университета леса, 2013. 164 с.

Tsarev A.P. Programs of forest breeding in Russia and abroad: monograph. Moscow: Publishing house of the Moscow State University of Forest, 2013. 164 p. (in Russian).

2. Ефимов Ю.П. Семенные плантации в селекции и семеноводстве сосны обыкновенной: монография. Научно-исследовательский институт лесной генетики и селекции. Воронеж: Изд-во Исток (Москва), 2010. 252 с.

Efimov Yu.P. Seed plantations in breeding and seed production of Scots pine: monograph. Scientific Research Institute of Forest Genetics and Breeding. Voronezh: Istok Publishing House (Moscow), 2010. 252 p. (in Russian).

3. Иозус А.П., Зеленяк А.К., Макаров В.М. Создание лесосеменных плантаций сосны и особенности их плодоношения в сухой степи Нижнего Поволжья // Современные проблемы науки и образования. 2013. № 4. [Электронный pecypc]. URL: http://science-education.ru/ru/article/ view?id=9826 (дата обращения: 21.07.2021).

4. Iozus A.P., Zelenyak A.K., Makarov V.M. Creation of pine seed plantations and features of their fruiting in the dry steppe of the Lower Volga region// Sovremennye problemy nauki i obrazovanija. 2013. № 4. [Electronic resource]. URL: http://science-education.ru/ru/article/view?id=9826 (date of access: 21.07.2021) (in Russian).

5. Морозова Е.В., Иозус А.П. Особенности плодоношения сосны обыкновенной и методы его стимулирования на семенных плантациях аридного региона юго-востока европейской территории России // Современные проблемы науки и образования. 2015. № 4. [Электронный ресурс]. URL: http://science-education.ru/ru/article/view?id=20586 (дата обращения: 21.07.2021).

6. Morozova E.V., Iozus A.P. Features of fruiting of Scots pine and methods of its stimulation on seed plantations of the arid region of the south-east of the European territory of Russia // Sovremennye problemy nauki i obrazovanija. 2015. № 4. [Electronic resource]. URL: http://science-education.ru/ru/article/ view?id=20586 (date of access: 21.07.2021) (in Russian).

7. Научно-методические указания по сортоводству деревьев и кустарников для защитного лесоразведения в аридных регионах. Волгоград: ВНИАЛМИ, 2013. 51 с.

Scientific and methodological guidelines for cultivating trees and shrubs for protective afforestation in arid regions. Volgograd: VNIALMI, 2013. 51 p. (in Russian).

8. Крючков С.Н., Киреева О.В. Опыт интродукции видов рода сосна (Pinus) в Нижнем Поволжье // Вестник Волгоградского государственного университета. Серия 11. Естественные науки. 2015. № 3(13). С. 18-27.

Kryuchkov S.N., Kireeva O.V. Experience of introduction of species of the genus pine (Pinus) in the Lower Volga region // Vestnik Volgogradskogo gosudarstvennogo universiteta. Serija 11. Estestvennye nauki. 2015. No. 3(13). P. 18-27 (in Russian).

9. Семенютина А.В., Костюков С.М., Кащенко Е.В. Методы выявления механизмов адаптации древесных видов в связи с их интродукцией в засушливые регионы // Успехи современного естествознания. 2016. № 2. С. 103-109.

Semenyutina A.V., Kostyukov S.M., Kashchenko E.V. Methods of identifying the mechanisms of adaptation of tree species in connection with their introduction to arid regions // Uspehi sovremennogo estestvoznanija. 2016. No. 2. P. 103109 (in Russian). 